\title{
MELHORAMENTO DO TRIGO: XIII. ESTIMATIVAS DE VARIÂNCIA, HERDABILIDADE E CORRELAÇÕES EM CRUZAMENTOS DE TRIGO PARA PRODUÇÃO DE GRÃOS E TOLERÂNCIA À TOXICIDADE DE ALUMINIO (1)
}

\author{
CARLOS EDUARDO DE OLIVEIRA CAMARGO $\left({ }^{2,3}\right)$
}

\section{RESUMO}

Estimaram-se os valores da herdabilidade para várias características da planta do trigo (tolerância ao $\mathrm{A}^{\beta+}$, comprimento da espiga, número de espiguetas por espiga e de grãos por espiga e por espigueta, peso de cem grăos, número de espigas por planta, altura das plantas e produção de grãos), bem como as correlaçōes entre a produção de grãos e a tolerância ao $\mathrm{AP}^{3+}$ com os demais caracteres agronômicos estudados. Os dados foram obtidos a partir de cruzamentos envolvendo o cultivar $\mathrm{BH}-1146$, tolerante ao $\mathrm{A}^{3+}$, e os cultivares Alondra-S-46 e IAC-17, moderadamente tolerantes. Plântulas parentais e as geraçōes $F_{1}$ e $F_{2}$ foram testadas para a reação a 3 e $6 \mathrm{mg} /$ ittro de $\mathrm{A}^{3+} \mathrm{em}$ soluçāo nutritiva. As plântulas, devidamente identificadas, foram transplantadas para vasos onde se desenvolveram até o final do ciclo vegetativo. A herdabilidade no sentido amplo para peso de cem grãos, comprimento da espiga e número de espiguetas por espiga foi, respectivamente, $0,73,0,69$ e 0,54. Para os demais caracteres, as herdabilidades foram baixas, variando de 0,09 a 0,24 . Os valores da herdabilidade no sentido restrito, para os caracteres estudados, com exceção do peso de cem

(1) Com recursos complementares do Acordo do Trigo ente as Cooperativas de Produtores Rurais do Vale do Paranapanema e a Secretaria de Agricultura e Abastecimento por meio do Instituto Agronómico. Recebido para publicaçăo em 22 de ägosto de 1986.

(2) Seção de Arroz e Cerais de Inverno, Instituto Agronômico (IAC), Caixa Postal 28, 13001 Campinas (SP).

( $\left.{ }^{3}\right)$ Com bolsa de suplementaçăo do CNPq. 
grãos e do número de espigas por planta, mostraram que grande parte da variabilidade genética nessas populaçōes é aditiva. As correlaçōes fenotípicas entre a produçāo de grāos e todos os demais caracteres agronômicos foram positivas e significativas para quase todas as populaçöes estudadas. A correlação entre produção de grãos e número de espiguetas por espiga para a população $\mathrm{BH}-1146 \times$ Alondra-S-46 foi negativa e significativa. Nessas populaçōes, a tolerância a 3 e $6 \mathrm{mg} /$ litro de $\left.A\right|^{3+}$ não foi associada com os caracteres agronômicos estudados, fazendo exceção a população $\mathrm{BH}-1146 \times \mid \mathrm{AC}-17$, que mostrou associaçōes significativas entre a tolerância a $3 \mathrm{mg} /$ /itro de $\mathrm{AP}^{3+}$ com altura das plantas, comprimento da espiga e número de espiguetas por espiga, e a população BH-1146 x Alondra-S-46, que apresentou associaçōes significativas entre a tolerância a $3 \mathrm{mg} / i$ tro de $\mathrm{A}^{3+} \mathrm{com}$ comprimento da espiga e número de espiguetas por espiga. Os resultados sugerem que seria possivel selecionar nas populaçōes estudadas plantas tolerantes ao $\mathrm{Al}^{3+}$, de porte semi-anão, com maior fertilidade da espiga e elevado potencial produtivo.

Termos de indexação: trigo, herdabilidade em sentido amplo, herdabilidade em sentido restrito, correlaçáo, toleråncia à toxicidade de aluminio, produçăo de grăos.

\section{INTRODUÇĀO}

As variedades de trigo diferem grandemente em relação à tolerância à toxicidade de alumínio em solos ácidos, bem como em soluçōes nutritivas (FOY et al., 1965; MUGMRA et al., 1981, e CAMARGO \& OLIVEIRA, 1981).

CAMARGO \& OLIVEIRA (1981) mostraram que os cultivares de trigo Siete Cerros e Tobari-66 foram sensiveis a 1 e $3 \mathrm{mg} /$ litro de aluminio na solução nutritiva respectivamente, enquanto Alondra-S-46 e $\mathrm{IAC}-17$ o foram a $6 \mathrm{mg} /$ litro. Os cultivares $\mathrm{BH}-1146, \mathrm{IAC}-5, \mathrm{IAC}-18, \mathrm{IAC}-13$ e Londrina foram tolerantes a 10 $\mathrm{mg} /$ litro de aluminio na solução nutritiva, sendo $\mathrm{BH}-1146$, IAC-18 e IAC-13 mais tolerantes que os outros. Em vasos contendo solo com alumínio, o BH-1146 diferiu, em produção de grãos por planta, dos cultivares Tobari-66, Alondra-S-46, IAC-17 e Siete Cerros.

Altos valores da herdabilidade em sentido amplo $(0,725$ a 0,895$)$ indicaram que a seleção para tolerância ao aluminio seria eficiente na população proveniente do cruzamento entre um cultivar tolerante - C-3, e um sensivel - Siete Cerros (CAMARGO, 1984).

CAMARGO (1981), estudando a herança da tolerância ao alumínio em solução nutritiva, mostrou que para $2 \mathrm{mg} /$ litro de aluminio, o cultivar de trigo Tordo diferiu de Siete Cerros por um par de genes dominantes para tolerância; para $3 \mathrm{mg} / \mathrm{litro}$, o $\mathrm{BH}-1146$ apresentou um par de genes e Atlas-66, dois pares de genes dominantes, quando foram cruzados com Siete Cerros e Tordo; para $6 \mathrm{mg} / \mathrm{litro}$ de Al, BH-1146 e Atlas-66, quando foram cruzados entre si, mostraram ter um par de genes dominantes cada um; o mesmo cruzamento entre $\mathrm{BH}-1146$ e 
Atlas-66, estudado a $10 \mathrm{mg} /$ litro, revelou que $\mathrm{BH}-1146$ diferiu do Atlas-66, que foi sensivel a essa concentração, com um par de genes dominantes para tolerância.

Trabalhos desenvolvidos por LAGOS et al. (1984) empregando plantas monossómicas $(2 n=41)$ de linhas aneuplóides e normais $(2 n=42)$ do genótipo de trigo Chinese Spring, identificadas citologicamente, que foram cruzadas com o ' $\mathrm{BH}-1146$ ', tolerante à toxicidade de $\mathrm{Al}^{3+}$, evidenciaram que a proporção de indivfduos tolerantes e sensiveis, entre progênies $F_{2}$, dos cruzamentos obtidos e testados em soluçōes nutritivas contendo $4 \mathrm{mg} / \mathrm{litro}$ de $\mathrm{Al}^{3+}$, era de $3: 1$, exceto entre descendentes das linhas monossômicas para o cromossoma 4D, onde o teste do quiquadrado não revelou ajuste, permitindo a conclusão de que o gene de tolerância ao $\mathrm{Al}^{3+}$ está localizado nesse segmento genético.

JOHNSON et al. (1966) encontraram valores altos de herdabilidade para altura das plantas, comprimento da espiga e peso dos grãos em cruzamentos envolvendo variedades de trigo de inverno, concluindo que as seleçōes para esses caracteres seriam eficientes na população $F_{2}$. CAMARGO (1984) obteve a mesma conclusão em relação a altura das plantas, número de grãos por espiga, comprimento da espiga e peso de cem grãos, com valores de herdabilidade de 0,720 a 0,885 , estudando cruzamentos entre um cultivar de porte semi-anão (Alondra-S-46) com três de porte alto (BH-1146, IAC-5 e C-3).

O estudo das associações entre os componentes de produção de uma população híbrida permite saber se os componentes são geneticamente dependentes ou independentes, isto é, se tendem ou não em permanecer associados nas progênies durante os sucessivos ciclos de seleção (FONSECA \& PATTERSON, 1968). Em populaçöes segregantes provenientes de cruzamentos de cultivares de trigo tolerantes e sensiveis à toxicidade de aluminio, verificou-se que essa tolerância não foi associada com altura das plantas (exceto para uma das populaçōes estudadas), produção de grãos e número de grãos por espigueta, sugerindo que seria possivel selecionar plantas tolerantes ao $\mathrm{Al}^{3+}$, de porte médio, com maior fertilidade da espiga e elevado potencial produtivo (CAMARGO, 1984).

No presente trabalho, estudou-se a herdabilidade em sentido amplo e restrito para oito caracteres agronômicos; as associaçōes entre a tolerância a 3 e $6 \mathrm{mg} / \mathrm{litro}$ de $\mathrm{Al}^{3+}$ em soluçăo nutritiva e a produção de grãos com caracteres agronômicos, a partir de populaçōes hibridas originárias de cruzamentos envolvendo três cultivares de trigo.

\section{MATERIAL E MÉTODOS}

Pesquisaram-se os seguintes cultivares: $\mathrm{BH}-1146$ (P1), IAC-17 (P2) e Alondra-S-46 (P3). O ' $\mathrm{BH}-1146$ ' é tolerante à toxicidade de aluminio e os demais, moderadamente tolerantes (CAMARGO, 1981). 
Foram obtidas as sementes em geração $F 1$ e $F 2$ dos cruzamentos BH-1146 x IAC-17 (P1 x P2), BH-1146 x Alondra-S-46 (P1 x P3) e IAC-17 x Alondra-S-46 (P2 x P3).

Os pais, F1s e F2s, foram testados para tolerância a 3 e $6 \mathrm{mg} /$ litro de alumínio em soluçōes nutritivas conforme o método descrito a seguir:

As sementes dos nove genótipos estudados foram cuidadosamente lavadas com uma solução de hipoclorito de sódio a $10 \%$ e colocadas para germinar em placas de Petri por 24 horas. Após esse tempo, as radiculas estavam iniciando a emergência.

Escolheram-se 24 sementes uniformes de cada cultivar utilizado como progenitor, 24 sementes de cada cruzamento em geração $F 1$ e 40 sementes de cada cruzamento em geraçāo F2, as quais foram colocadas sobre o topo de cada uma das quatro telas de náilon a utilizar. Cada uma das telas contendo as sementes dos nove genótipos foi deixada em contacto com a solução nutritiva completa existente em quatro vasilhas plásticas de 8,3 litros de capacidade cada uma.

A concentração final da solução nutritiva completa foi a seguinte: $\mathrm{Ca}\left(\mathrm{NO}_{3}\right)_{2} 4 \mathrm{mM} ; \mathrm{MgSO}_{4} 2 \mathrm{mM} ; \mathrm{KNO}_{3} 4 \mathrm{mM} ;\left(\mathrm{NH}_{4}\right)_{2} \mathrm{SO}_{4}$ 0,435 mM; $\mathrm{KH}_{2} \mathrm{SO}_{4} 0,5 \mathrm{mM}$; $\mathrm{MnSO}_{4} 2 \mu \mathrm{M}$; $\mathrm{CuSO}_{4} 0,3 \mu \mathrm{M} ; \mathrm{ZnSO}_{4} 0,8 \mu \mathrm{M}$; $\mathrm{NaCl} 30 \mu \mathrm{M}$; FeCYDTA $10 \mu \mathrm{M}$; $\mathrm{Na}_{2} \mathrm{MoO}_{4} 0,1 \mu \mathrm{M}$ e $\mathrm{H}_{3} \mathrm{BO}_{3} 10 \mu \mathrm{M}$. O nivel da solução nas vasilhas plásticas foi de tal modo a tocar a parte de baixo da tela de náilon; assim, as sementes eram mantidas úmidas $\mathrm{e}$ as radiculas emergentes tinham um pronto suprimento de água e de nutrientes. $\mathrm{O} \mathrm{pH}$ da soluçēo foi previamente ajustado para 4,0 com uma soluçāo de $\mathrm{H}_{2} \mathrm{SO}_{4} 1 \mathrm{~N}$. As soluçōes foram continuamente arejadas e, as vasilhas plásticas, colocadas em banho-maria com temperatura de $25 \pm 1{ }^{\circ} \mathrm{C}$ no laboratório. $O$ experimento foi mantido com luz fluorescente em sua totalidade. As plântulas desenvolveram-se nessas condiçōes por 48 horas. Decorrido esse período, cada plântula apresentava três raízes primárias, uma mais longa, medindo cerca de 4,5 cm, e duas mais curtas, localizadas lateralmente à primeira. Duas das telas de náilon foram transferidas para soluçōes tratamentos contendo $3 \mathrm{mg} / \mathrm{litro}$ de $\mathrm{Al}^{3+}$ e duas para soluçōes tratamentos contendo $6 \mathrm{mg} /$ litro de $\mathrm{Al}^{3+}$ na forma de $\mathrm{Al}_{2}\left(\mathrm{SO}_{4}\right)_{3} 18 \mathrm{H}_{2} \mathrm{O}$. Essas concentraçōes foram escolhidas com base em estudos anteriores, que mostraram ser tais niveis eficientes para a separaçāo de plantas tolerantes e sensiveis ao $\mathrm{Al}^{3+}$ (CAMARGO, 1981).

A composição da solução tratamento foi de um décimo da solução nutritiva completa, exceto que o fósforo foi omitido e o ferro foi adicionado em quantidade equivalente, como $\mathrm{FeCl}_{3}$, no lugar de FeCYDTA. O fósforo foi omitido para evitar a possível precipitação do alumínio. Por causa da precipitação do alumínio como Al $(\mathrm{OH})_{3}$, especial atenção foi dada a esse ponto. Antes de serem transferidas as telas para as soluçōes de tratamento, suficiente solução de $\mathrm{H}_{2} \mathrm{SO}_{4} 1 \mathrm{~N}$ foi adicionada, para trazer o pH para cerca de 4,2 e então a necessária quantidade de aluminio como $\mathrm{Al}_{2}\left(\mathrm{SO}_{4}\right)_{3} \quad 18 \mathrm{H}_{2} \mathrm{O}$ foi colocada visando obter soluçöes com $3 \mathrm{e}$ 
$6 \mathrm{mg} /$ litro de $\mathrm{Al}^{3+}$. $\mathrm{O} \mathrm{pH}$ final foi ajustado para 4,0 com uma solução de $\mathrm{H}_{2} \mathrm{SO}_{4} 1 \mathrm{~N}$, evitando-se adicionar $\mathrm{NaOH}$, que poderia causar a precipitação do alumínio pelo menos no local de queda da gota. As plântulas cresceram por 48 horas nas soluçōes de tratamento. Passado esse periodo, as quatro telas contendo as plântulas dos nove genótipos foram transferidas de volta para as vasilhas contendo solução nutritiva completa, onde cresceram nas primeiras 48 horas.

As plântulas desenvolveram-se nas soluçōes completas por 72 horas. O crescimento da raiz após as 72 horas na solução completa depende da severidade da prévia solução tratamento. Com uma quantidade tóxica de aluminio para determinado genótipo, as raizes primárias não crescem mais e permanecem grossas, mostrando no ápice uma injúria típica com descoloramento. A quantidade de crescimento da raiz foi determinada, medindo-se o crescimento da raiz de cada plântula no final das 72 horas na solução nutritiva completa e subtraindo-se o comprimento da mesma ralz medida no tinal de crescimento na soluçäo de tratamento.

Após a medição das ralzes, as plântulas foram transferidas para vasos preenchidos com solo adubado, sem alumínio trocável, localizados no telado contra ataque de pássaros no Centro Experimental de Campinas; devidamente identificadas quanto à tolerância a 3 e $6 \mathrm{mg} /$ litro de $\mathrm{Al}^{3+}$ em solução nutritiva, foram plantadas em número de quatro por vaso, equidistantes uma da outra.

$O$ delineamento estatistico empregado foi de blocos ao acaso com nove tratamentos, os quais incluem os 3 pais, os $3 \mathrm{~F} 1 \mathrm{~s}$ e os $3 \mathrm{~F} 2 \mathrm{~s}$, com quatro repetiçōes. As duas primeiras repetiçōes foram constituidas de plantas testadas em soluçōes de tratamento contendo $3 \mathrm{mg} /$ litro de $\mathrm{Al}^{3+} e$ as duas repetiçōes restantes, das plantas testadas em soluçóes contendo $6 \mathrm{mg} /$ litro de $\mathrm{Al}^{3+}$. Cada repetição foi formada por seis vasos de cada genitor e de cada híbrido em geração $F 1$, e por dez vasos de cada híbrido em geração F2. O conjunto das quatro repetiçöes foi constituído de 264 vasos de plástico preto de aproximadamente $25 \mathrm{~cm}$ de altura e $20 \mathrm{~cm}$ de diâmetro. Os vasos foram distribuidos distantes um do outro na linha de $10 \mathrm{~cm}$ e, entre as linhas, de $40 \mathrm{~cm}$. Plantou-se uma linha adicional de vasos contornando o experimento visando minimizar os efeitos de bordadura.

Os seguintes dados foram coletados em plantas individuais:

Tolerância ao alumínio - Considerada como o crescimento, em milimetro, da raiz primária central em 72 horas na soluçāo nutritiva completa, após um tratamento de 48 horas em solução nutritiva contendo 3 e $6 \mathrm{mg} / \mathrm{litro}$ de $\mathrm{Al}^{3+}$.

Altura da planta - Medida, em centímetros, do nivel do solo até o ápice das espigas, excluindo as aristas.

Espigas por planta - Considerado apenas o número de colmos com espigas férteis. cada planta.

Produção de grãos - Peso, em gramas, da produção total de grãos de 
Comprimento da espiga - Medida, em centímetros, da espiga do colmo principal, excluindo as aristas.

Espiguetas - Computado o número de espiguetas do colmo principal.

Grãos por espiga - Número total de grãos da espiga do colmo principal.

Grãos por espigueta - Número resultante da divisão do total de grãos da espiga principal pelo total de espiguetas da mesma espiga.

Peso de cem grãos - Peso, em gramas, de cem grãos coletados ao acaso na produção total da planta.

Os caracteres estudados foram submetidos à análise de variância e o teste $F$, aplicado para testar os tratamentos. Para a análise de variância, considerou-se a média de cada genótipo em cada repetição. Os efeitos de geração foram divididos em componentes para detectar diferenças entre e dentro de geraçöes. A estimativa da herdabilidade no sentido amplo (proporçăo da variância genética total em relação à variância fenotípica) foi calculada conforme o método citado por BRIGGS \& KNOWLS (1977). A estimativa da herdabilidade em sentido restrito foi calculada pela regressão da média de $F_{2}$ em cada repetição sobre o respectivo $F_{1}$, segundo FALCONER (1960), considerando os três cruzamentos em Conjunto.

As correlaçōes fenotípicas, genotipicas e ambientes foram usadas para estimar o grau de associação entre a produçâo de grâos e sete outros caracteres agronômicos para cada uma das três populações (P1 x P2, P1 x P3 e P2 x P3). Calcularam-se também as correlaçōes fenotipicas, genotipicas e ambientes entre a tolerância a 3 e $6 \mathrm{mg} /$ itro de $\mathrm{Al}^{3+}$ e oito caracteres agronómicos para as três populaçōes. Como sugerido por FALCONER (1960), as correlaçōes usando dados de F1 foram consideradas ambientes $e$ aquelas com dados de F2, fenotípicas. As genotípicas foram calculadas pela seguinte fórmula:

$$
r_{F}=\sqrt{H_{x}} \sqrt{H_{y}} \quad r_{G}+\sqrt{E_{x}} \sqrt{E_{y}} \quad r_{A}
$$

onde:

$\mathrm{r}_{\mathrm{F}}=$ correlação fenotípica entre os caracteres $\mathrm{x}$ e $\mathrm{y}$;

$r_{G}=$ correlação genotípica entre $x$ e $y$;

$r_{A}=$ correlação ambiente entre $x$ e $y$;

$H_{x}$ e $H_{y}=$ herdabilidades em sentido restrito para os caracteres $x$ e $y$ respectivamente, considerando os três cruzamentos em conjunto;

$$
E_{x}=1-H_{x}, E_{y}=1-H_{y} \text {. }
$$




\section{RESULTADOS E DISCUSSÃO}

No quadro 1, encontram-se as análises de variância para comprimento da raiz (tolerância a 3 e $6 \mathrm{mg} /$ litro de $\mathrm{Al}^{3+}$ ). No quadro 2, as análises de variância para comprimento da espiga; número de espigueta e de grãos por espiga; peso de cem grãos; número de grãos por espigueta; altura das plantas; número de espigas por planta e produçāo de grãos, e, no quadro 3 , as médias de cada genótipo para cada um dos caracteres estudados.

Aplicando o teste de Tukey a $5 \%$ para a comparação entre o comprimento da raiz, após 72 horas em solução nutritiva completa, seguido de um crescimento de 48 horas em solução contendo $3 \mathrm{mg} /$ litro de $\mathrm{Al}^{3+}$, verificou-se que o ' $\mathrm{BH}-1146$ ' foi o mais tolerante, diferindo dos cultivares IAC-17 e Alondra-S-46; IAC-17 foi mais tolerante a essa concentração de $A^{3+}$ em relação a 'Alondra-S-46', confirmando os resultados obtidos por CAMARGO \& OLIVEIRA (1981).

QUADRO 1. Análise de variância para comprimento da raiz de genótipos parentais, $F_{1}$ e $F_{2}$ dos cruzamentos para tolerância a dois niveis de aluminio em trigo

\begin{tabular}{|c|c|c|c|}
\hline \multirow{3}{*}{$\begin{array}{c}\text { Causas de } \\
\text { variaçăăo }\end{array}$} & \multirow{3}{*}{ G.L. } & \multicolumn{2}{|c|}{ Q.M. } \\
\hline & & \multicolumn{2}{|c|}{ Comprimento da raiz } \\
\hline & & $3 \mathrm{mg} / \mathrm{de} \mathrm{Al}^{3+}$ & $6 \mathrm{mg} / \mathrm{de} A \mathrm{P}^{\beta+}$ \\
\hline & & - & _- \\
\hline Repetiçōes & 1 & 0,43 & 0,32 \\
\hline Genótipos & (8) & $164,26^{* *}$ & $84,84^{* *}$ \\
\hline Entre geraçōes & 2 & 90,71 & $123,89^{* \star}$ \\
\hline Dentro de geraçōes & (6) & $188,78^{* *}$ & $71,83^{\star \star}$ \\
\hline Pais & 2 & $306,59^{\star *}$ & $181,07^{\star \star *}$ \\
\hline$F_{1} s$ & 2 & $128,01^{*}$ & 3,61 \\
\hline$F_{2} s$ & 2 & $131,76^{*}$ & $30,81^{*}$ \\
\hline Genótipos x rep. & (8) & 2,09 & 1,42 \\
\hline Entre ger. $x$ rep. & 2 & 4,96 & 0,85 \\
\hline Dentro ger. $x$ rep. & (6) & 1,13 & 1,61 \\
\hline Pais $x$ rep. & 2 & 0,22 & 2,58 \\
\hline$F_{1} s \times$ rep. & 2 & 1,70 & 0,95 \\
\hline$F_{2} s \times$ rep. & 2 & 1,46 & 1,32 \\
\hline Total & 17 & & \\
\hline
\end{tabular}

" = Significativo a $5 \%$ pelo teste $F . "=$ Significativo a $1 \%$ pelo teste $F$. 


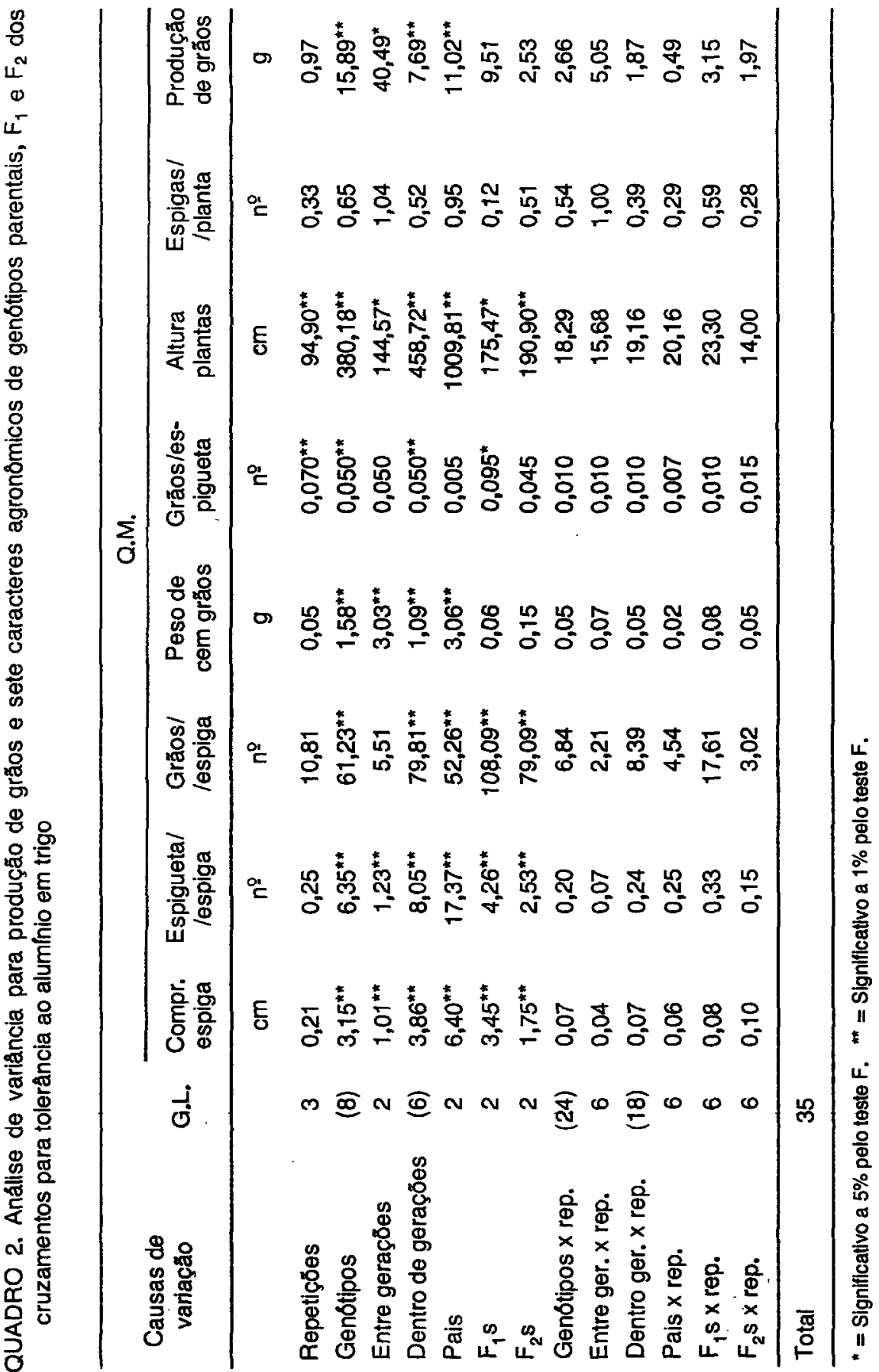


MELHORAMENTO DO TRIGO: XIHI. ESTIMATIVAS DE VARIÂNCIA...

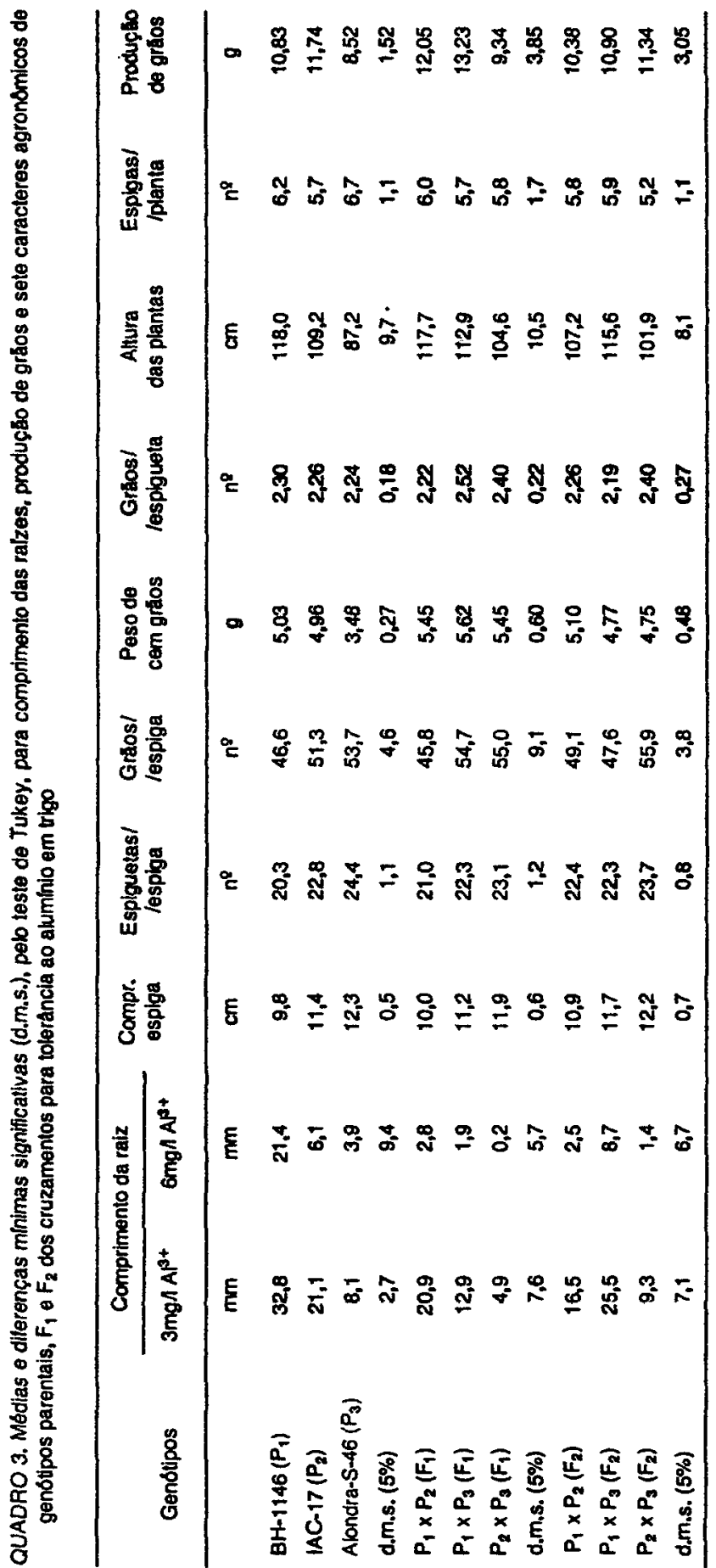


O híbrido $\mathrm{IAC}-17 \times$ Alondra-S-46 em geração F1 exibiu menor crescimento de raiz, diferindo significativamente dos demais. Quando se utilizaram soluçōes de tratamento contendo $6 \mathrm{mg} / \mathrm{litro}$ de $\mathrm{Al}^{3+}$, ' $\mathrm{BH}-1146$ ' foi o mais tolerante, diferindo dos cultivares IAC-17 e Alondra-S-46, que não diferiram entre si. Não se detectaram diferenças significativas entre os $\mathrm{F} 1 \mathrm{~s}$ em relação à tolerância a 6 $\mathrm{mg} /$ litro de $\mathrm{Al}^{3+}$. O híbrido $\mid \mathrm{AC}-17 \times$ Alondra-S-46 em geração F2 também apresentou menor crescimento das ralzes nessa concentração de $\mathrm{Al}^{3+}$, diferindo, porém, somente do híbrido $\mathrm{BH}-1146 \times$ Alondra-S-46.

Em relação ao comprimento da espiga, o 'Alondra-S-46' apresentou as espigas mais compridas, diferindo significativamente do 'IAC-17 e do 'BH-1146'. Este apresentou as espigas mais curtas, diferindo significativamente do "IAC-17. O hibrido IAC-17 x Alondra-S-46 em geração F1 mostrou espigas mais compridas que as do hibrido $\mathrm{BH}-1146 \times$ Alondra-S-46, não diferindo deste, porém diferindo das do híbrido $\mathrm{BH}-1146 \times$ IAC-17. O hibrido IAC-17 $\times$ Alondra-S-46 em geraçāo F2 diferiu dos demais, com as espigas mais compridas. Alondra-S-46 poderia ser utilizado em um programa de cruzamentos como fonte de espiga comprida, pois mostrou-se eficiente em transmitir esta caracteristica às suas progênies.

O 'Alondra-S-46' apresentou mais espiguetas por espiga, diferindo significativamente dos cultivares $\mid \mathrm{AC}-17$ e $\mathrm{BH}-1146$, que diferiram entre si: 0 'BH-1146' apresentou menos espiguetas por espiga. O hibrido 'IAC-17' $\times$ 'AlondraS-46' em geraçōes F1 e F2 apresentou o maior número de espiguetas por espiga, diferindo dos demais, com exceção do 'BH-1146' x 'Alondra-S-46' em geração F1. 0 'Alondra-S-46' mostra tendências de elevar o número de espiguetas por espiga das populaçōes em relação aos demais cultivares.

Considerando o número de grãos por espiga, 'Alondra-S-46' e 'IAC-17' mostraram maior indice, diferindo significativamente do 'BH-1146'. O genótipo IAC-17 x Alondra-S-46 em geração F1 apresentou o maior número de grãos por espiga, porém somente diferiu estatisticamente do $\mathrm{BH}-1146 \times$ IAC-17. Entre os híbridos em geração F2, o IAC-17 x Alondra-S-46 foi o que apresentou maior número de grãos por espiga, diferindo significativamente dos demais. 'IAC-17 e 'Alondra-S-46' mostraram-se promissores em transmitir aos seus descendentes a característica maior número de grãos por espiga.

Os cultivares $\mathrm{BH}-1146$ e IAC-17 exibiram os grãos mais pesados, diferindo apenas do 'Alondra-S-46, confirmando os resultados obtidos por McLUNG et al. (1986), onde as linhagens de trigo de porte alto apresentaram consistentemente grãos mais pesados em relação às de porte semi-anão. Não se detectaram diferenças significativas em relação ao peso de cem grăos entre os híbridos estudados em geração F1 e F2.

Considerando o número de grãos por espigueta, não houve diferenças significativas entre os cultivares pais e os F2s. O híbrido BH-1146 x Alondra-S-46, em geração $\mathrm{F} 1$, apresentou maior número de grãos por espigueta, diferindo significativamente, porém, só do híbrido $\mathrm{BH}-1146$ x IAC-17. 
O 'Alondra-S-46' apresentou a menor altura, diferindo significativamente dos outros dois cultivares de porte alto, que não diferiram entre si. $O$ híbrido $\mathrm{BH}-1146 \times 1 \mathrm{AC}-17$, em geraçäo $\mathrm{F} 1$, teve as plantas mais altas, diferindo, porém, somente do híbrido IAC-17 x Alondra-S-46. O BH-1146 x Alondra-S-46, em geração F2, mostrou as plantas mais altas, diferindo significativamente dos demais.

Não se detectaram diferenças significativas entre os cultivares pais, F1s e F2s em relação ao número de espigas por planta.

Em relação à média de produção de grãos, os cultivares $\mid A C-17$ e BH-1146 apresentaram os maiores valores, não diferindo entre si, mas sim do 'Alondra-S-46'. O híbrido BH-1146 x Alondra-S-46, em geração $\mathrm{F}$ 1, mostrou a maior produção de grāos, diferindo, porém, apenas do IAC-17 x Alondra-S-46. As médias das populaçōes $F 1$, com exceção da proveniente do híbrido IAC-17 $\dot{x}$ Alondra-S-46, foram superiores às médias de ambos os pais, evidenciando heterose para esse caráter. Esses resultados também foram encontrados por JOHNSON et al. (1966) e CAMARGO et al. (1980). Não se detectaram diferenças significativas para produção de grãos nos híbridos em geração $F 2$.

0 quadro 4 apresenta as estimativas das herdabilidades em sentido amplo $\left(\mathrm{H}_{\mathrm{BS}}\right)$ e restrito $\left(\mathrm{H}_{\mathrm{NS}}\right)$, para todos os caracteres estudados, derivadas de dados obtidos nas geraçōes parentais, F1s e F2s das três populaçōes híbridas.

QUADRO 4. Herdabilidade em sentido amplo e restrito para dez caracteres de trigo envolvendo três genótipos parentais e seus cruzamentos

\begin{tabular}{|c|c|c|}
\hline Carăter & $\mathrm{H}_{\mathrm{BS}}\left({ }^{1}\right)$ & $\mathrm{H}_{\mathrm{NS}}{ }^{(2)}$ \\
\hline Altura das plantas $(\mathrm{cm})$ & 0,29 & 0,37 \\
\hline Produção de grãos (g) & 0,13 & 0,16 \\
\hline Comprimento da espiga $(\mathrm{cm})$ & 0,69 & 0,64 \\
\hline Espiguetas/espiga (n9) & 0,54 & 0,47 \\
\hline Grãos/espiga ( $\left.n^{\circ}\right)$ & 0,09 & 0,25 \\
\hline Gräos/espigueta (nº) & 0,24 & 0,19 \\
\hline Peso de cem grãos $(\mathrm{g})$ & 0,73 & 0,21 \\
\hline Espigas/planta ( $\left.n^{\circ}\right)$ & 0,11 & 0,03 \\
\hline Comprimento da raiz $\left(3 \mathrm{mg} / /\right.$ de $\left.\mathrm{Al}^{3+}\right)$ & - & 0,70 \\
\hline Comprimento da raiz $\left(6 \mathrm{mg} / \mathrm{de} \mathrm{A}^{3+}\right)$ & - & 0,54 \\
\hline
\end{tabular}

(1) $\mathrm{H}_{\mathrm{BS}}=$ Herdabilidade em séntido amplo. $\left({ }^{2}\right) \mathrm{H}_{\mathrm{NS}}=$ Herdabilidade em sentido restrito. 
Os valores estimados para a herdabilidade em sentido amplo foram altos para peso de cem grãos e comprimento da espiga; médios para número de espiguetas por espiga e baixos para altura das plantas, produção de grãos, número de grảos por espiga e por espigueta e número de espigas por planta. Esses valores indicam que grande parte das variaçōes obtidas para os dois primeiros caracteres são de origem genética, nas populaçōes estudadas, confirmando os resultados de JOHNSON et al. (1966).

Os valores da herdabilidade em sentido restrito foram menores do que os da herdabilidade em sentido amplo, exceto para a altura das plantas, produção de grāos e número de grāos por espiga, onde foram ligeiramente superestimados pelo método da regressão.

Os valores da herdabilidade em sentido restrito para comprimento da espiga e comprimento da raiz aposs um tratamento em soluçōes contendo $3 \mathrm{mg} / \mathrm{litro}$ de $\mathrm{Al}^{3+}$ foram altos; para número de espiguetas por espiga e comprimento da raiz após um tratamento em soluçōes contendo $6 \mathrm{mg} / \mathrm{litro}$ de $\mathrm{Al}^{3+}$, médios, e para altura das plantas, produçāo de grāos, número de grāos por espiga e por espigueta, peso de cem grãos e número de espigas por planta, baixos. Esses resultados indicam que grande parte da variabilidade genética total para comprimento da espiga, comprimento das raizes após um tratamento em soluçōes contendo $3 \mathrm{e}$ $6 \mathrm{mg} /$ litro de $\mathrm{Al}^{3+}$ e número de espiguetas por espiga, é devida a genes que se comportam de maneira aditiva, corroborando os resultados de CAMARGO (1984) e CAMARGO et al. (1980). KETATA et al. (1976), estudando oito caracteres agronômicos em um cruzamento de trigo de inverno, concluíram que os efeitos aditivos foram a principal fonte de variação para peso de cem grãos, indicando que seleçōes nas primeiras geraçōes deveriam ser realizadas. Para os demais caracteres em estudo, os dados sugerem que a seleçāo poderia ser efetuada nas últimas geraçōes quando o valor genético da progênie seria mais precisamente determinado (KETATA et al., 1976).

As correlaçōes ambientais $\left(r_{A}\right)$, fenotipicas $\left(r_{F}\right)$ e genéticas $\left(r_{G}\right)$ entre produção de grãos e sete outros caracteres agronômicos para os cruzamentos envolvendo os três cultivares de trigo encontram-se no quadro 5.

As correlaçōes fenotípicas entre a produção de grãos e os demais caracteres agronômicos foram positivas e altamente significativas ao nivel de $1 \%$, exceto entre a produção e o número de espiguetas por espiga para a população BH-1146 x IAC-17, que foi positiva e significativa ao nivel de 5\%; entre a produçầo e o número de espiguetas por espiga para a população $\mathrm{BH}-1146 \times$ Alondra-S-46, que foi negativa e significativa ao nivel de $5 \%$; entre produção de grāos e comprimento da espiga e entre produçăo de grãos e altura das plantas para a população BH-1146 x Alondra-S-46, e entre produção de grãos e número de espiguetas por espiga para a população IAC-17 x Alondra-S-46, que foram não-significativas. Associaçōes positivas entre produçāo de grãos e altura das plantas foram também observadas por JOHNSON et al. (1966). Correlações positivas e altamente significativas entre produção de grãos e oito caracteres agronômicos foram obtidas por CAMARGO \& OLIVEIRA (1983). 
QUADRO 5. Correlaçōes ambientes, fenotipicas e genotipicas entre produção de grãos e sete outros caracteres agronômicos em três cruzamentos de trigo

\begin{tabular}{|c|c|c|c|c|}
\hline Caráter & $\begin{array}{l}\text { Correla- } \\
\text { ção }\left({ }^{1}\right)\end{array}$ & $\begin{array}{c}\mathrm{BH}-1146 \\
\times \\
\mathrm{IAC}-17\end{array}$ & $\begin{array}{c}\text { BH-1146 } \\
\times \\
\text { Alondra-S-46 }\end{array}$ & $\begin{array}{c}\text { IAC-17 } \\
x \\
\text { Alondra-S-46 }\end{array}$ \\
\hline \multirow[t]{3}{*}{ Peso de cem grãos ( $(\mathrm{g})$} & $r_{A}$ & $0,39^{* *}$ & 0,09 & 0,20 \\
\hline & $r_{F}^{n}$ & $0,32^{* *}$ & $0,59^{* *}$ & $0,55^{* *}$ \\
\hline & $r^{\prime} G$ & 0,34 & $>1,00$ & $>1,00$ \\
\hline \multirow[t]{3}{*}{ Grãos/espigueta ( $\left.n^{\circ}\right)$} & $r_{A}$ & $0,74^{* *}$ & $0,63^{* *}$ & $0,63^{* \star}$ \\
\hline & $r_{F}^{A}$ & $0,55^{* *}$ & $0,44^{* *}$ & $0,53^{* *}$ \\
\hline & $r_{G}^{\prime}$ & $-0,36$ & $-0,47$ & 0,07 \\
\hline \multirow[t]{3}{*}{ Grãos/espiga $\left(n^{\circ}\right)$} & $r_{A}$ & $0,73^{\star *}$ & $0,49^{* *}$ & $0,72^{* *}$ \\
\hline & $r_{F}^{n}$ & $0,52^{* *}$ & $0,42^{\star \star}$ & $0,56^{* *}$ \\
\hline & $r_{G}$ & $-0,28$ & 0,17 & $-0,06$ \\
\hline \multirow[t]{3}{*}{ Espiguetas/espiga $\left(n^{\circ}\right)$} & $r_{A}$ & 0,25 & 0,24 & $0,47^{\star \star}$ \\
\hline & $r_{F}$ & $0,19^{*}$ & $0,22^{*}$ & 0,15 \\
\hline & $r_{G}$ & 0,09 & $<-1,00$ & $-0,63$ \\
\hline \multirow[t]{3}{*}{ Comprimento da espiga (cm) } & $r_{A}$ & $0,54^{\star \star}$ & $0,46^{* \star}$ & $0,68^{* \star}$ \\
\hline & $r_{F}$ & $0,38^{* *}$ & $-0,06$ & $0,38^{* *}$ \\
\hline & $r_{G}$ & 0,25 & $-0,98$ & 0,02 \\
\hline \multirow[t]{3}{*}{ Altura das plantas $(\mathrm{cm})$} & $r_{A}$ & $0,39^{* *}$ & $0,41^{* \star}$ & $0,36^{*}$ \\
\hline & $r_{F}$ & $0,26^{* *}$ & 0,12 & $0,34^{* *}$ \\
\hline & ${ }^{\prime} \mathrm{G}$ & $-0,07$ & $-0,73$ & 0,33 \\
\hline \multirow[t]{3}{*}{ Espigas/planta $\left(n^{\circ}\right)$} & $r_{A}$ & $0,84^{* *}$ & $0,66^{\star \star}$ & $0,96^{\star \star}$ \\
\hline & $r_{F}^{n}$ & $0,54^{* *}$ & $0,40^{* *}$ & $0,59^{* *}$ \\
\hline & $r_{G}$ & $<-1,00$ & $<-1,00$ & $-0,12$ \\
\hline
\end{tabular}

$\left({ }^{1}\right) r_{A}=$ correlação ambiente; $r_{F}=$ correlação fenotipica; $r_{G}=$ correlaçāo genotpica

"= Significativo ao nivel de $5 \%$. " = Significativo ao nivel de $1 \%$.

No quadro 6 , encontram-se as correlações ambientes $\left(r_{A}\right)$, fenotipicas $\left(r_{F}\right)$ e genotipicas $\left(r_{G}\right)$ entre o comprimento da raiz medida nos tratamentos de 3 e $6 \mathrm{mg} / \mathrm{litro}$ de $\mathrm{Al}^{3+} \mathrm{e}$ oito caracteres agronômicos para os cruzamentos envolvendo os cultivares $\mathrm{BH}-1146, \mathrm{AC}-17$ e AlondraS-46. 
QUADRO 6. Correlaçōes ambientes, fenotficicas e genotípicas entre o comprimento de ralzes testadas em soluçōes nutritivas contendo 3 e $6 \mathrm{~m}$.ghitro de $\mathrm{A}^{\beta+}$ e oito caracteres agronômicos

\begin{tabular}{|c|c|c|c|c|c|c|c|}
\hline \multirow{3}{*}{ Carăter } & \multirow{3}{*}{$\begin{array}{l}\text { Correla- } \\
\text { ção }\left({ }^{(}\right)\end{array}$} & \multicolumn{6}{|c|}{ Cruzamentos } \\
\hline & & \multicolumn{2}{|c|}{$\begin{array}{c}\mathrm{BH}-1146 \\
\times \\
\text { IAC-17 }\end{array}$} & \multicolumn{2}{|c|}{$\begin{array}{c}\mathrm{BH}-1146 \\
\mathrm{x} \\
\text { Alondra-S-46 }\end{array}$} & \multicolumn{2}{|c|}{$\begin{array}{c}\text { IAC-17 } \\
x \\
\text { Alondra-S-46 }\end{array}$} \\
\hline & & $3 \mathrm{mg} n$ & $6 m g /$ & $3 \mathrm{mg} /$ & $6 \mathrm{mg} / 1$ & $3 \mathrm{mg} /$ & $6 \mathrm{mg} /$ \\
\hline \multirow[t]{3}{*}{ Produção de grãos (9) } & $\mathrm{r}_{\mathrm{A}}$ & 0,35 & 0,07 & 0,13 & $0,53^{* *}$ & 0,19 & 0,33 \\
\hline & $r_{F}^{A}$ & 0,20 & $-0,01$ & 0,09 & 0,20 & 0,11 & 0,15 \\
\hline & $r_{G}^{r}$ & 0,07 & $-0,18$ & 0,93 & $-0,43$ & 0,05 & $-0,19$ \\
\hline \multirow[t]{3}{*}{ Altura das plantas $(\mathrm{cm})$} & $r_{A}$ & 0,04 & 0,08 & $-0,21$ & 0,17 & $-0,17$ & 0,15 \\
\hline & $r_{F}^{A}$ & $0,36^{\star *}$ & 0,22 & 0,21 & $-0,01$ & $-0,23$ & $-0,04$ \\
\hline & $r_{G}$ & 0,67 & 0,40 & 0,59 & $-0,21$ & $-0,31$ & $-0,28$ \\
\hline \multirow[t]{3}{*}{ Grãos/espigueta (nº) } & $r_{A}$ & $0,49^{\star *}$ & $-0,03$ & $-0,15$ & $0,51^{*}$ & 0,23 & 0,27 \\
\hline & $r_{F}^{A}$ & 0,01 & 0,01 & 0,18 & 0,14 & 0,06 & $-0,16$ \\
\hline & $r_{G}^{r}$ & $-0,65$ & 0,08 & 0,68 & 0,56 & $-0,15$ & $<-1,00$ \\
\hline \multirow[t]{3}{*}{ Comprimento da espiga $(\mathrm{cm})$} & $r_{A}$ & 0,28 & $-0,03$ & 0,06 & $0,50^{*}$ & $-0,04$ & 0,11 \\
\hline & $\mathrm{r}_{\mathrm{F}}^{\mathrm{A}}$ & $0,40^{* *}$ & 0,06 & $0,31^{*}$ & $-0,07$ & $-0,11$ & $-0,07$ \\
\hline & $r_{G}^{r}$ & 0,58 & 0,11 & 0,46 & $-0,17$ & $-0,17$ & 0,13 \\
\hline \multirow[t]{3}{*}{ Espiguetas/espiga $\left(n^{\circ}\right)$} & $r_{A}$ & 0,29 & 0,16 & 0,01 & 0,16 & 0,23 & $-0,12$ \\
\hline & $r_{F}^{A}$ & $-0,40^{* *}$ & $-0,10$ & $0,37^{\star *}$ & $-0,03$ & $-0,17$ & 0,17 \\
\hline & $r_{G}$ & $-0,58$ & $-0,23$ & 0,64 & $-0,09$ & $-0,32$ & 0,36 \\
\hline \multirow[t]{3}{*}{ Grãos/espiga (nํ) } & $r_{A}$ & $0,59^{\star \star}$ & 0,14 & $-0,12$ & $0,46^{*}$ & 0,26 & 0,23 \\
\hline & $\mathrm{F}$ & $-0,19$ & $-0,03$ & 0,36 & 0,14 & $-0,05$ & $-0,04$ \\
\hline & $r_{G}^{r}$ & $-0,56$ & $-0,13$ & 0,88 & 0,21 & $-0,17$ & 0,19 \\
\hline \multirow[t]{3}{*}{ Peso de cem grāos $(g)$} & $r_{A}$ & $-0,11$ & 0,07 & 0,05 & $-0,04$ & $-0,18$ & 0,02 \\
\hline & $r_{F}^{A}$ & 0,13 & $-0,13$ & $-0,25$ & 0,18 & 0,13 & 0,01 \\
\hline & $r_{G}^{r}$ & 0,31 & $-0,42$ & $-0,67$ & 0,56 & 0,38 & 0,02 \\
\hline \multirow[t]{3}{*}{ Espigas/planta $\left(\mathrm{n}^{\mathrm{O}}\right)$} & $r_{A}$ & 0,28 & 0,03 & 0,17 & $0,43^{*}$ & 0,29 & 0,37 \\
\hline & $r_{F}^{A}$ & 0,29 & 0,17 & 0,24 & 0,01 & 0,05 & 0,11 \\
\hline & $r_{G}^{r}$ & $>1,00$ & $>1,00$ & $>1,00$ & $-0,75$ & 0,08 & 0,23 \\
\hline
\end{tabular}

(1) $r_{A}=$ correlaçăo ambiente; $r_{F}=$ correlaçăo fenotípica; $r_{G}=$ correlaçăo genotípica.

* = Significativo ao nivel de $5 \% . *$ Significativo ao nivel de $1 \%$. 
Nos cruzamentos estudados, a tolerância a $3 \mathrm{mg} / \mathrm{litro}$ de $\mathrm{Al}^{3+}$ não foi associada com altura das plantas (com exceção da correlaçăo fenotípica no cruzamento BH-1146 x (AC-17); produção de grăos; número de grãos por espigueta e por espiga; peso de cem grãos e número de espigas por planta. As correlaçōes fenotlipicas entre tolerância a $3 \mathrm{mg} / \mathrm{litro}$ de $\mathrm{Al}^{3+}$ e comprimento da espiga nos cruzamentos $\mathrm{BH}-1146 \times$ IAC-17 e $\mathrm{BH}-1146 \times$ Alondra-S-46 foram positivas e significativas e para o cruzamento IAC-17 $\times$ Alondra-S-46 não foi significativa. Para o cruzamento $\mathrm{BH}-1146 \times \mathrm{AC}-17$, a correlação fenotipica entre a tolerância a $3 \mathrm{mg} /$ litro de $\mathrm{Al}^{3+}$ e o número de espiguetas por espiga foi negativa e significativa; para o $\mathrm{BH}-1146 \times$ Alondra-S-46 foi positiva e significativa, e para o IAC-17 $\times$ $x$ Alondra-S-46 não foi significativa. A tolerância a $6 \mathrm{mg} / \mathrm{litro}$ de $\mathrm{Al}^{3+}$ também não foi associada a esses caracteres agronômicos, confirmando os resultados de CAMARGO (1984). Considerando essas correlaçōes, verifica-se que seria possivel selecionar, nas populaçōes segregantes em estudo, plantas tolerantes ao alumínio, de porte médio, com maior fertilidade da espiga e de alto potencial produtivo, que seriam adaptadas à maioria dos solos ácidos existentes nas regiōes triticolas brasileiras.

\author{
SUMMARY \\ WHEAT BREEDING, \\ XIII. VARIANCE, HERITABILITY AND CORRELATIONS \\ IN WHEAT CROSSES FOR GRAIN YIELD \\ AND TOLERANCE TO ALUMINUM TOXICITY
}

The aluminum tolerant cultivar $\mathrm{BH}-1146$ was crossed with the moderately tolerant cultivars IAC-17 and Alondra-S-46. Parents, F1's and F2's were tested for their seedling reaction to 3 and $6 \mathrm{ppm}$ of $\mathrm{A}^{3+}$ in nutrient solution. Grain yield, plant height, number of spikes per plant, number of spikelets per spike, number of grains per spike, number of grains per spikelet, 100-grain-weight and spike lenght were also determined for these populations at maturity. All data were determined on an individual plant basis. Broad sense heritability estimates for 100-grain-weight, head lenght and number of spikelets per spike were $0.73,0.69$ and 0.54 respectively. The values for plant height, number of grain per spike and per spikelet, and number of spike per plant ranged from 0.09 to 0.29 . Broad sense heritability for grain yield was low and equal to 0.13. Narrow sense heritability estimates for all characteristics under study except for 100-grain-weigth and number of spikes per plant showed that a major part of the total genetic variation was associated with additive gene action. The phenotypic correlations between grain yield and all the other characteristics were positive and significant at $1 \%$ level for most of the populations. Correlations between grain yield and number of spikelets per spike, in populations $\mathrm{BH}-1146 \times 1 \mathrm{AC}-17$, showed to be positive and signifcant only at the $5 \%$ probability level. Grain yield and number of spikelets per 
spike in population $\mathrm{BH}-1146 \times$ Alondra-S-46 were negative and significantly correlated only at the $5 \%$ probability level. Non significant correlations between grain yield and head lenght and between grain yield and plant height in population $\mathrm{BH}-1146 \times$ Alondra-S-46 and between grain yield and number of spikelets per spike in population IAC-17 $\times$ Alondra-S-46. Tolerance to 3 and $6 \mathrm{ppm}$ of $\mathrm{AP}^{\mathrm{B}}$ in nutrient solutions was not associated with plant height (except for $\mathrm{BH}-1146 \times \mathrm{AC}-17$ at $3 \mathrm{ppm}$ of $\mathrm{Al}^{3+}$ ), grain yield, number of grains per spikelet (head fertility), spike lenght (except for $\mathrm{BH}-1146 \times$ IAC-17 and $\mathrm{BH}-1146 \times$ Alondra-S-46 at $3 \mathrm{ppm}$ of $\mathrm{AP}^{3+}$ ), number of spikelets per spike (except for $\mathrm{BH}-1146 \times 1 \mathrm{AC}-17$ and $\mathrm{BH}-1146 \times$ Alondra-S-46 at $3 \mathrm{ppm}$ of $\left.A^{3+}\right)$, number of grain per spike, 100-grain-weight and number of spike per plant. The results suggested that there is a possibility of selecting plant types that combine $\mathrm{Al}^{3+}$ tolerance, semi-dwarf height levels and high yield potential, to be grown on acid soils.

Index terms: wheat, broad sense heritability, narrow sense heritability, correlation, tolerance, aluminum toxicity, grain yield, plant height, head fertility.

\section{REFERÊNCIAS BIBLIOGRÁFICAS}

BRIGGS, F.N. \& KNOWLES, P.F. Introduction to plant breeding. Davis, Reinhold Publishing Corporation, 1977, 426p.

CAMARGO, C.E.O. Melhoramento do trigo. I. Hereditariedade da tolerância ao alumínio tóxico. Bragantia, Campinas, 40:33-45, 1981.

- Melhoramento do trigo. VI. Hereditariedade da tolerância a três concentraçōes de alumínio em solução nutritiva. Bragantia, Campinas, 43(2):279-291, 1984.

- Melhoramento do trigo. X. Estimativas das herdabilidades e correlaçōes entre tolerância à toxicidade de alumínio e produção de grãos com outros caracteres agronômicos em trigo. Bragantia, Campinas, 43(2):615-628, 1984.

; KRONSTAD, W.E. \& METZGER, R.J. Plant-progeny regression estimates and associations of height levels with aluminum toxicity and grain yield in wheat. Crop Science, 20:355-358, 1980.

\& OLIVEIRA, O.F. Melhoramento do trigo V: estimativas da herdabilidade e correlaçōes entre altura, produção de grãos e outros caracteres agronômicos em trigo. Bragantia, Campinas, 42:131-148, 1983.

$\&$ - Tolerância de cultivares de trigo a diferentes niveis de aluminio em solução nutritiva e no solo. Bragantia, Campinas, 40:21-31, 1981.

FALCONER, D.S. Introduction to quantitative genetics. New York, Ronald Press, 1960. 365p.

FONSECA, S. \& PATTERSON, F.L. Yield components, heritabilities and interrelationships in winter wheat (Triticum aestivum L.). Crop Science, 8:614-617, 1968.

FOY, C.D.; ARMIGER, W.H.; BRIGGLE, LW. \& REID, D.A. Differential aluminum tolerance of wheat and barley varieties in acid soils. Agronomy Journal, 57:413-417, 1965. 
JOHNSON, V A.; BIEVER, K.J.; HAUNOLD, A.; SCHMIDT, J.W. Inhentance of plant height, yield of grain, and other plant and seed characteristics in a cross of hard red winter wheat (Triticum aestivum L.). Crop Science, 6:336-338, 1966.

KETATA, H.; EDWARDS, L.H.; SMITH, E.L. Inheritance of eight agronomic characters in a winter wheat cross. Crop Science, 16:19-22, 1976.

LAGOS, M.B.; FERNANDES, M.I.B.M.; CARVALHO, F.I.F. \& CAMARGO, C.E.O. Localização do gene(s) de tolerância ao crestamento em trigo cv. BH-1146 (Triticum aestivum L.) Trabalho apresentado na $13^{\mathrm{a}}$ Reuniăo Nacional de Pesquia de Trigo, Cruz Alta, 1984. 1p.

MCLUNG, A.M.; CANTRELL, R.G.; QUICK, J.S. \& GREGORY, R.S. Influence of the Rht 1 semidwarf gene on yield, yield components, and grain protein in durum wheat. Crop Science, 26: 1095-99, 1986.

MUGWIRA, L.M.; SAPRA, V.T.; PATEL, S.U. \& CHOUDRY, M.A. Aluminum tolerance of triticale and wheat cultivars developed in different regions. Agronomy Journal, 73:470-475, 1981. 